\title{
Behavioural response of sicklefin lemon sharks Negaprion acutidens to underwater feeding for ecotourism purposes
}

\author{
Eric Clua ${ }^{1,2, *}$, Nicolas Buray ${ }^{3}$, Pierre Legendre ${ }^{4}$, Johann Mourier ${ }^{3}$, Serge Planes ${ }^{3}$ \\ ${ }^{1}$ Secretariat of the Pacific Community, BPD5, 98848 Noumea, New Caledonia \\ ${ }^{2}$ Ministère de l'Agriculture et de la Pêche, 251 Rue de Vaugirard, Paris 15, France \\ ${ }^{3}$ Centre de Recherches Insulaires et Observatoire de l'Environnement (CRIOBE - USR 3278 EPHE CNRS), BP 1013, \\ 98729 Moorea, French Polynesia \\ ${ }^{4}$ Département de sciences biologiques, Université de Montréal, CP 6128, succursale Centreville, Montréal, \\ Québec H3C 3J7, Canada
}

\begin{abstract}
The feeding of marine predators is a popular means by which tourists and tour operators can facilitate close observation and interaction with wildlife. Shark-feeding has become the most developed provisioning activity around the world, despite its controversial nature. Amongst other detrimental effects, the long-term aggregation of sharks can modify the natural behaviour of the animals, potentially increase their aggression toward humans, and favour inbreeding. During 949 diving surveys conducted over $44 \mathrm{mo}$, we investigated the ecology and residence patterns of 36 photoidentified adult sicklefin lemon sharks Negaprion acutidens. The group contained 20 females and 16 males. From this long-term survey, we identified 5 different behavioural groups that we described as 'new sharks' (7), 'missing sharks' (4), 'resident sharks' (13), 'unpredictable sharks' (5) and 'ghost sharks' (7). In spite of movements in and out of the area by some males and females, which were probably related to mating, the general trend was that residency significantly increased during the study, particularly in males, showing a risk of inbreeding due to the reduction of shark mobility. Intraand interspecific aggression was also witnessed, leading to an increased risk of potentially severe bites to humans. Our findings suggest the need for a revision of the legal framework of the provisioning activity in French Polynesia, which could include a yearly closure period to decrease shark behavioural modifications due to long-term shark-feeding activities.
\end{abstract}

KEY WORDS: Shark-feeding $\cdot$ Provisioning $\cdot$ Human disturbance $\cdot$ Behaviour $\cdot$ Site residence

\section{INTRODUCTION}

Large predators, which are potentially dangerous to humans and often feared, account for a substantial proportion of ecotourism activities based on animal sightings. However, because of their generally elusive nature and locally low population densities, such predators are often difficult to observe. Sharks are shy animals (Bres 1993), and provisioning is necessary to produce reliable and impressive aggregations of animals. The last decade has seen tremendous development of ecotourism based on the sighting of top marine predators (Orams 2002, Topelko \& Dearden 2005). The practice of shark-feeding is widespread throughout the tropical and subtropical seas of the world, e.g. in the Bahamas, Fiji, South Africa, Australia and French Polynesia, and it is becoming controversial, with little consensus about how it should be managed. Deliberate and long-term shark-feeding is suspected to generate problems for both animals and humans (Dobson 2006, Newsome \& Rodger 2008). It may alter the natural behavioural patterns of sharks, generating biological (for the animal themselves) and ecological (for the ecosystem) effects. Provisioning may cause habituation to human contact and increase aggression towards humans by associating divers with food (Burgess 1998, 
Orams 2002). However, feeding wildlife can be a positive tool for assisting in the conservation of vulnerable and endangered species, through attaching economic value to wildlife and educating tourists about the need for conservation (Bookbinder et al. 1998, Halpenny 2003); it can also increase the probability of a shark encountering a partner as a result of aggregation (Orams 2002). Despite the controversy, few, if any, comprehensive reports have measured the impact of shark-feeding, which is now widespread and growing around the world.

To date, studies have been conducted on the effect of chumming on white shark Carcharodon carcharias in South Africa (Johnson \& Kock 2006, Laroche et al. 2007), as well as sandbar Carcharhinus plumbeus and Galapagos C. galapagensis sharks in Hawaii (Meyer et al. 2009). These studies all concluded that moderate levels of provisioning of cage-diving ecotourism probably had a minor impact on the behaviour of the sharks and no risk of increased attacks on humans in adjacent areas. In South Africa, Johnson \& Kock (2006) showed that conditioning only arises if white sharks gain significant and predictable food rewards, which only happens if operators contravene permit regulations prohibiting intentional feeding of sharks. White sharks are lured to the boat with baits (typically, mashed sardines and fish oil; Laroche et al. 2007) that are significantly different from their usual prey in the area, Cape fur seals Arctocephalus pusillus pusillus (Ferreira \& Ferreira 1996). In Hawaii, Meyer et al. (2009) showed that cage-diving activities did not increase the number of attacks on humans, probably due to the fact that the shark tours use a small amount of fish scraps, mimicking the activities of crab fishing vessels which have been operating in the same area for over $40 \mathrm{yr}$. In both cases, while some food is used to attract sharks to the cages for observation and photography, the quantities involved are small, so this activity cannot be considered as real 'provisioning'. Light baiting is also used at Aliwal Shoal (South Africa) for attracting tiger sharks Galeocerdo cuvier and allowing encounters with snorkelers in open water (Dicken \& Hosking 2009). However, the available scientific data focus on the economic value of the recreational activity, and do not address its effects on the behaviour of these potentially dangerous sharks (ISAF 2010). Bull sharks Carcharhinus leucas, another dangerous species (ISAF 2010), have been attracted to an ecotourism site in Beqa (Fiji Islands) since 2002 through a real feeding and conditioning process based on the release of several tuna heads during each dive (E. Clua pers. obs.); here again, however, the only data provided are socio-economic (Brunnschweiler 2010), with no reference to the biological issues of provisioning of carnivorous animals. Given the controversial nature of shark-feeding, there is a critical need for empirical studies that focus on potentially dangerous sharks, and address both the potential disruption of their natural behaviour, which underpins their resilience, and the increasing risk of fatal attacks on humans (Garrod \& Wilson 2006).

In French Polynesia, sharks are fed daily during diving activities. The main species involved, the sicklefin lemon shark Negaprion acutidens, can reach over $3 \mathrm{~m}$ in length and is considered to be potentially dangerous to humans (Maillaud \& Van Grevelynghe 2005, ISAF 2010). This coastal shark is widely distributed in the Indo-Pacific, from Eastern Africa to French Polynesia. However, very little is known about the ecology of the sicklefin lemon shark in the Central Pacific. Despite its commercial value (Compagno 1984), only a few studies have been conducted in the Indian Ocean (Stevens 1984) and in Western Australia (White et al. 2004) besides a recent global genetic study (Schultz et al. 2008). The ecology of its sister species, the Atlantic lemon shark $N$. brevirostris, has been well documented during past decades (Gruber 1982, Chapman et al. 2009), mostly in the central Western Atlantic Ocean. However, while its early life has been extensively studied (Morrissey \& Gruber 1993, DiBattista et al. 2007), very little is known about the adult stages of $N$. brevirostris and even less about $N$. acutidens.

Moorea Island (French Polynesia) is among the few locations worldwide where it is possible and feasible to have daily encounters with several wild adult sicklefin lemon sharks in their natural environment. This characteristic provided us with an opportunity to investigate the behaviour and residency pattern of an adult population of this reef shark species through daily underwater observations at a provisioning tourism location. Here, we describe the population size and structure of this species, aggregated for ecotourism purposes at a site on the northern outer reef of Moorea Island. We divided the population into co-occurrence groups and describe the residence patterns and behaviour of these groups. We also tested the hypothesis that shark-feeding increases the fidelity of lemon sharks to the site, and discuss the potential long-term effects on population resilience and behaviour, including the risk of increased interactions with humans.

\section{MATERIALS AND METHODS}

Study implementation. The study was conducted at Moorea Island $\left(17^{\circ} \mathrm{S}, 149^{\circ} \mathrm{W}\right)$ in the Society Islands Archipelago, French Polynesia. Shark-feeding activities started there in the late 1980s, in the lagoon, passes and outer slope of the barrier reef. In October 2004, Moorea authorities implemented a Management Plan for the Marine Environment (Plan de Gestion de 
l'Espace Maritime, PGEM) that restricted sharkfeeding activities to 2 zones. Our specific study area was located at Papetoai on the outer slope of the reef (from $149^{\circ} 50^{\prime} 670^{\prime \prime}$ to $149^{\circ} 51^{\prime} 389^{\prime \prime} \mathrm{W}$ ); it was selected for its abundance of sicklefin lemon sharks (Buray et al. 2009). At this site, 3 different diving centres feed the sharks between 08:00 and 10:30 h. Our feeding sessions were conducted in the presence of tourist divers through dives at depths of 20 to $25 \mathrm{~m}$, starting at 09:00 $\mathrm{h}$ and lasting 60 to $100 \mathrm{~min}$. Sessions consisted of placing a small cage containing tuna discards on the substratum at the beginning of each dive to lure and aggregate the sharks in the area. The food was released at the end of the dive for the benefit of 1 or sometimes 2 sharks. Data on the presence or absence of sharks were recorded on each dive using natural identification marks on their bodies (Buray et al. 2009), photographed with a digital camera when necessary. Part of the identification process included the determination of sex from the presence or absence of claspers, and total length, estimated visually. We cross-checked the reliability of this visual assessment through a laser measurement of some individuals, based on the projection of 2 laser light spots, $43 \mathrm{~cm}$ apart, onto the flank of the shark as it was photographed (Bansemer \& Bennett 2008). DNA sampling with a biopsy probe mounted on a spear gun was also conducted on $80 \%$ of the sharks for paternity analysis (the subject of a complementary study), which also allowed us to assess the reliability of the photo-identification process through genetic fingerprinting.

The data analysed in the present paper comprise 36 sicklefin lemon sharks observed during 949 dives spanning $1338 \mathrm{~d}$, or more than $3.5 \mathrm{yr}$. The study started on 2 January 2005, and ran until 31 August 2008. The animals are numbered F01 to M38 (F: female, M: male). Sharks numbered 14 and 22 are not included in the present study as they were photo-identified only once in the provisioning area.

Statistical methods. Females F32 and F33 and males M34 to M38 arrived at the study site late in the study and were seldom seen (2 to 19 times each, for a total of 51 sightings of these 7 ind.), and never in groups. The earliest sighting was on Day 692 of the study (animal M34). These 7 ind. were excluded from the following analyses; they were considered as a separate group.

For the 29 remaining sharks, we computed a square $(29 \times 29)$ matrix showing how many times each pair of animals was observed during the 949 dives. That value is usually called $a$ in descriptions of binary similarity indices like the Jaccard and Sørensen coefficients (Legendre \& Legendre 1998); and we follow this usage in this paper. This statistic can be tested for significance against the null hypothesis $H_{0}$ that there is no association between these 2 sharks. We developed an
R function to carry out the test of a by permutation, following the method originally proposed by Raup \& Crick (1979) and detailed by Legendre \& Legendre (1998, p. 273). The function produced 2 outputs: a $(29 \times$ 29) matrix of coefficients $a$ and a $(29 \times 29)$ matrix of $\mathrm{p}$ values (after 9999 random permutations) associated with the coefficients.

We used the matrix of $p$ values to delineate groups of lemon sharks. An initial total of 406 tests of significance were computed. The Holm (1979) correction for multiple testing was applied to the $\mathrm{p}$ values to obtain an experiment-wise error rate of $5 \%$. After correction, the 52 pairs of animals that had a coefficients with original $p$ values of 0.0001 or less remained significant. Agglomerative clustering methods were not useful for this study because the groups were not clearly isolated from one another and some individuals belonged to 2 groups. We therefore examined the connections among animals on a graph obtained by principal coordinate ordination of the matrix of significant $p$ values (Gower 1966, Legendre \& Legendre 1998).

We used simple linear regression analysis to relate the abundances of the sharks, globally and in groups, to days since the beginning of the survey, in order to determine which group, if any, displayed increased fidelity to the site. The regression lines were plotted on graphs showing how many sharks of each group were observed during each dive.

\section{RESULTS}

\section{Population size and structure}

The 36 observed sharks comprised 20 females $(55.5 \%)$ and 16 males $(44.5 \%)$. Total length (TL) of the identified sicklefin lemon sharks ranged from 230 to $310 \mathrm{~cm}$, with a mean of $273 \pm 24 \mathrm{~cm}(95 \%$ confidence interval, Fig. 1). The sex ratio was slightly in favour of females all year long but varied during any given year, with the number of males decreasing during the reproductive season, around October (Fig. 2). Overall, this population was made up of adults larger than $230 \mathrm{~cm}$, which are assumed to be sexually mature at that size (Stevens 1984).

\section{Residence patterns and grouping}

Fig. 3 presents the co-occurrence links between sharks in the principal coordinate ordination plot. The first 2 principal coordinate axes accounted for $21 \%$ of the variance in the matrix of $\mathrm{p}$ values, which is sufficient for such a representation. One can make out 5 groups, with the largest possibly containing 2 subgroups. 


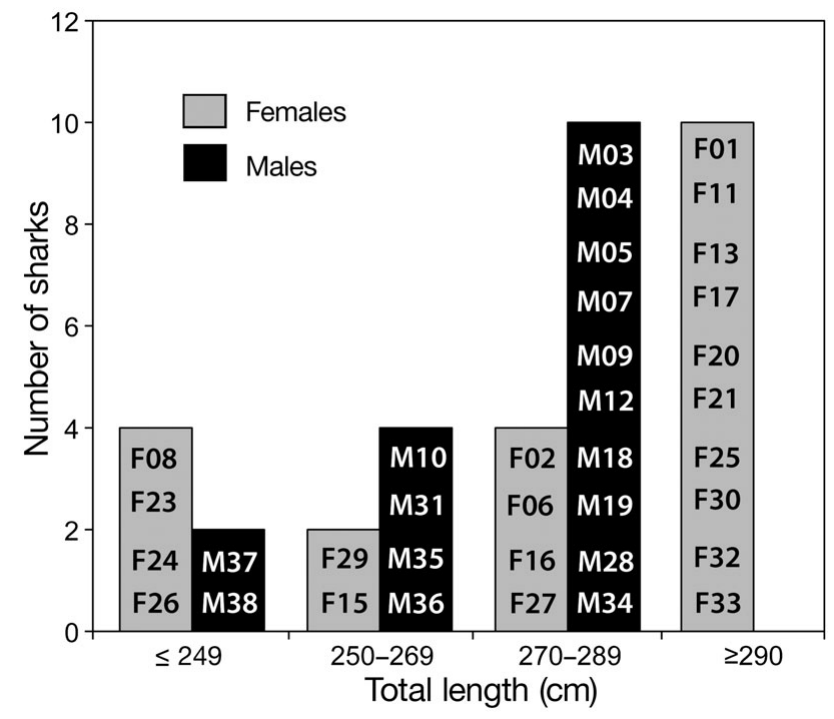

Fig. 1. Negaprion acutidens. Size distribution of the 36 male and female sicklefin lemon sharks at the Moorea sharkfeeding site. Individual sharks are identified in the histogram bars

Group A (51 sightings in total), designated 'new sharks', comprised females F32 and F33 and males M34 to M38. They arrived at the site late in the study (first sighting on Day 692). These individuals were seldom observed, and no more than one was seen during a dive (Fig. 4A), as described in the statistical methods above. Because of their peculiar time distrib-

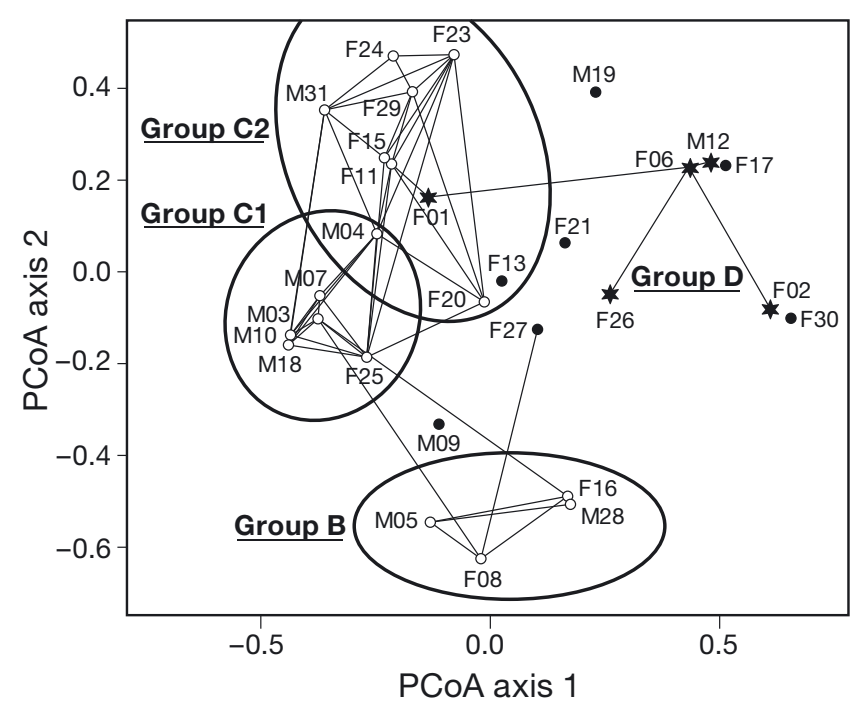

Fig. 3. Negaprion acutidens. Principal coordinate analysis (PCoA) ordination showing the co-occurrence links among sharks with a $\mathrm{p}$ value of 0.0001 . The first 2 PCoA axes together account for $21 \%$ of the variation in the matrix of $p$ values among the 29 sharks. Groups B, C1 and C2 are identified by ellipses, and Groups D and E by asterisks and black dots, respectively

ution, they displayed a strong significant increase with time (Table 1). This grouping was more a result of late occurrence than any real interaction grouping. However, it demonstrates a renewal of the pool that gained 7 new individuals (20\%) in a single year.

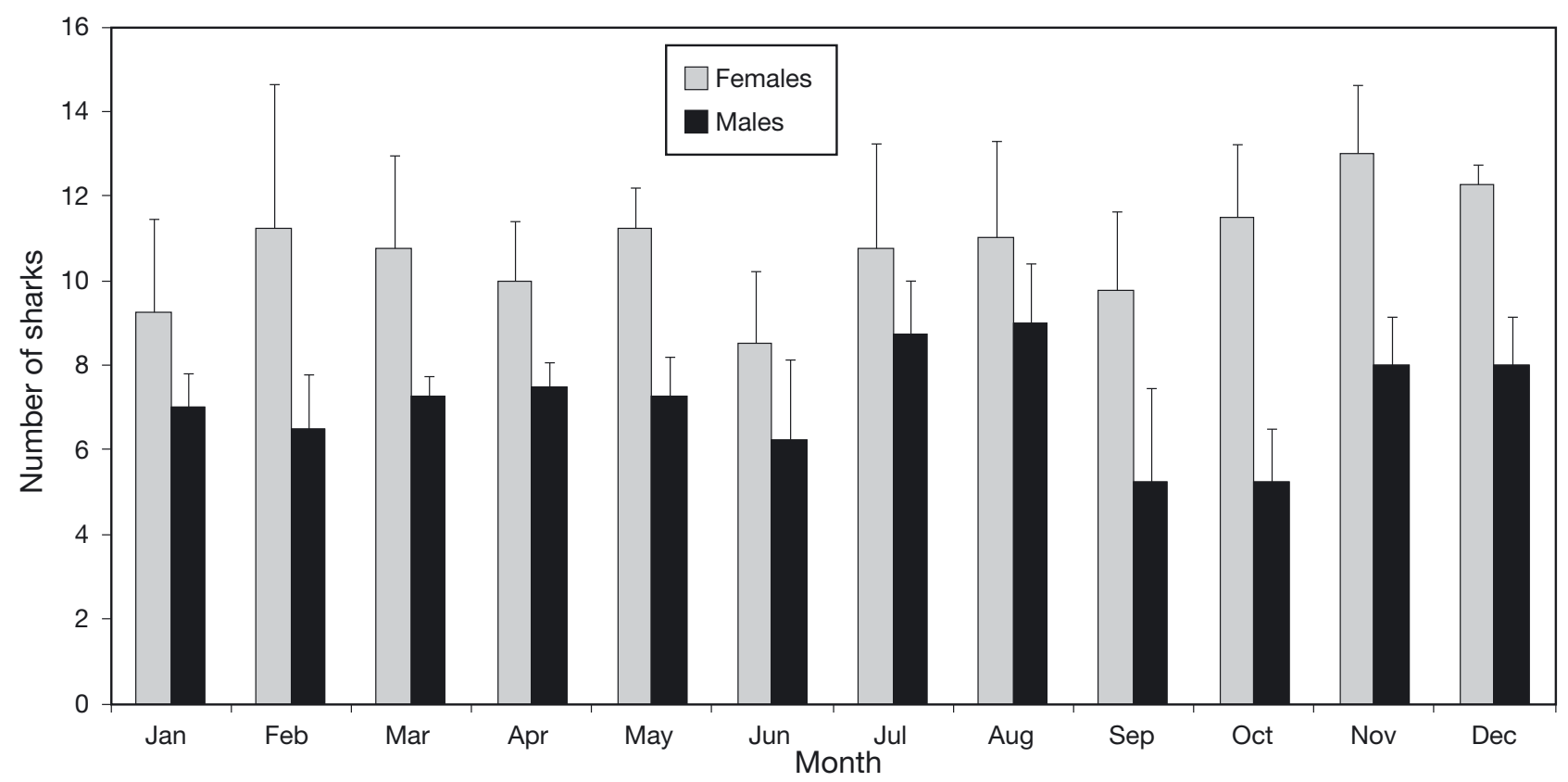

Fig. 2. Negaprion acutidens. Mean number of male and female sharks in each month of the year after 44 mo of observation with $95 \%$ confidence intervals (error bars) 

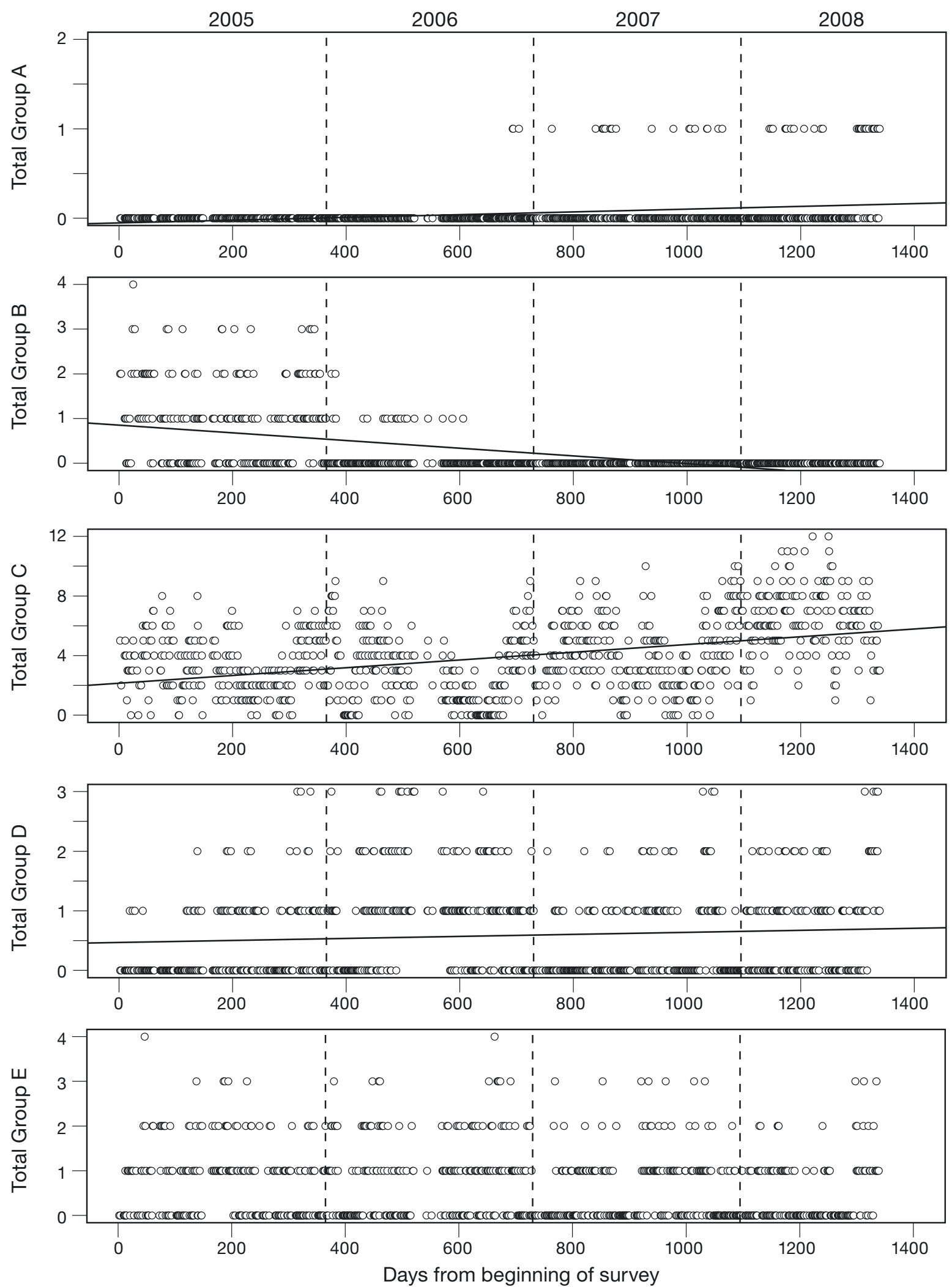

Fig. 4. Negaprion acutidens. Total number of sharks in a group (A to E are the group identifiers) observed during the 949 dives (days from the beginning of the survey along the abscissa). The linear regression line is shown in each graph, except for Group E. Vertical dashed lines are year divisions $(2005,2006,2007,2008)$ 
Table 1. Negaprion acutidens. Simple linear regression results for the relationships between the number of sharks, globally and in groups (except Group E), observed during 949 dives, and the number of days since the beginning of the survey. The slope values are very small because the day numbers range from 2 to 1339

\begin{tabular}{|lccl|}
\hline & Slope & $\mathrm{p}$-value & Interpretation \\
\hline All sharks $(\mathrm{n}=36)$ & 0.00176 & $2.05 \times 10^{-12}$ & Strong significant increase \\
Group A & $1.542 \times 10^{-4}$ & $3.68 \times 10^{-16}$ & Strong significant increase \\
Group B & $-8.588 \times 10^{-4}$ & $<2 \times 10^{-16}$ & Strong significant decrease \\
Group C & 0.00260 & $<2 \times 10^{-16}$ & Strong significant increase \\
Group C1 & 0.00033 & 0.0151 & Slight significant increase \\
Group C2 & 0.00252 & $<2 \times 10^{-16}$ & Strong significant increase \\
Group D & $1.677 \times 10^{-4}$ & 0.0103 & Slight significant increase \\
\hline
\end{tabular}

Group B (246 sightings), called 'missing sharks', contained the 4 strongly interconnected sharks (M05, F08, F16, M28) at the bottom of Fig. 3. F27 was not included in that group for 2 reasons: it was only associated with F08 and it was seen at the site during the whole study, whereas the members of Group B were only observed up to Day 606 (Fig. 4B). This is the only group that displayed a strong significant decrease (Table 1): it was present in 2005 but disappeared during 2006.

Group C (3739 sightings), designated 'resident sharks', was the largest group, with 13 ind. (M03, M04, M07, M10, F11, F15, M18, F20, F23, F24, F25, F29, M31), and was composed of 2 subgroups. The pivotal male M04 belonged to both subgroups C1 and C2. This male showed some atypical dominance behaviour. As the study progressed, in addition to a strong residency pattern, this shark showed increasing aggression towards its male and female conspecifics and, to a lesser degree, toward divers (N. Buray pers. obs.).

Subgroup C1 (1877 sightings) contained 6 sharks (M03, M04, M07, M10, M18, F25), all of which were males except F25. It showed a slight but significant increase in sightings over time (Table 1).

Subgroup C2 (2137 sightings) included 8 sharks (M04, F11, F15, F20, F23, F24, F29, M31), all of which were female except M04 and M31. It showed a strong significant increase in sightings over time, particularly in the last 2 yr (Table 1).

Group D (556 sightings), designated 'unpredictable sharks', contained 5 loosely interconnected sharks (F01, F02, F06, M12, F26) of which all were female except M12. Female F06 played a pivotal role in this group. The group showed a slight but significant increase in sightings over time (Table 1 ).

Group E (617 sightings), designated 'ghost sharks', contained 7 ungrouped individuals (M09, F13, F17, M19, F21, F27, F30). All except F27 had no co-occurrence link at the 0.0001 significance level.

\section{DISCUSSION}

This is the first detailed study to address the effects of provisioning on sharks by providing observational data which describe the response of these predators to a multi-annual daily feeding in a natural environment. It provides complementary information about a different type of feeding (conducted underwater), on a different species (lemon shark), than previous studies which addressed the effects of surface chumming on white sharks in South Africa (Laroche et al. 2007), or cage diving on Galapagos and sandbar sharks in Hawaii (Meyer et al. 2009).

Our statistical analysis allowed us to classify the 36 sharks into 6 groups $(\mathrm{A}, \mathrm{B}, \mathrm{C} 1, \mathrm{C} 2, \mathrm{D}, \mathrm{E})$, based on the affinity between sharks and their fidelity to the site. Groups A and E, each composed of 7 sharks, were of limited interest, as they comprised sharks that were either too late in coming to the feeding site to determine any significant pattern, or displayed unpredictable behaviour with no clear pattern. However, it is interesting to notice a clear turn-over in the population with the arrival of new individuals that became established. The 4 sharks composing Group B had a resident pattern in 2005 but disappeared from the study site during 2006. This may be explained by death (i.e. M05, which appeared to be old), stress due to shark intraspecific interactions (see below) or just temporary disappearance (i.e. M28, which re-appeared in 2008 after a 2 yr absence).

Group C, which comprised 13 'resident' sharks, showed a strong pattern of sexual segregation. Subgroup C1 was mostly composed of males (5 males and 1 female), and subgroup C2 was mostly composed of females (6 females and 2 males), with male M04 showing strong affinities with both subgroups. This spatial and temporal sexual segregation is commonly encountered in carcharhinids (Klimley 1987, Economakis \& Lobel 1998) and other shark families (Bansemer \& Bennett 2008, Mucientes et al. 2009). Male sharks of Subgroup C1 (1877 sightings) showed strong residency during all $4 \mathrm{yr}$; their presence rate decreased strongly in October-November, corresponding with the mating period (Stevens 1984). This trend may be due to a temporary migration for mating with females that do not belong to the studied population. In fact, reproduction has been recognised as a driving factor for spatial segregation between sexes in other studies (Economakis \& Lobel 1998). Sharks from Subgroup C2 (2137 sightings) mostly comprised females which seemed to aggregate at the 
feeding site and leave for only a few days for parturition (easily detected by external shape of the belly), as witnessed between August and October in 2005 and 2007 (for F11, F15 and F20), in September 2007 (F23) and in August and October 2008 (F24 and F29; N. Buray pers. obs.).

We considered the 'unpredictable' sharks from Group D, comprising 4 females and 1 male (556 sightings), as 'non-residents'. This term is based mainly on the consideration of the cumulative number of days at the site; it does not refer to a pattern of regular yearly presence at the feeding site during the extended mating period (July to November). This pattern can be seen as the inverse of the disappearance of the C1 sharks in October-November. As some 'resident' males were leaving the study site for mating, some females may have arrived for the same purpose. Genetic investigations on the lemon shark Negaprion brevirostris in the Bahamas (Feldheim et al. 2002) have shown that to avoid inbreeding problems within their relatively small populations, they appear to have developed a mating strategy. Whereas female lemon sharks return to their natal grounds each year, males remain nomadic, only infrequently returning to the same mating group. In our study, we found a similar pattern of 'mixing population' in $N$. acutidens, mainly with females potentially coming back to their natal grounds; however, unlike $N$. brevirostris in the Bahamas, males showed a strong residency and site attachment over the years. Assuming similarity in the natural behaviour of these 2 sister species, our findings could be linked to an aggregating effect of shark-feeding, which decreases the mobility of animals, mainly the males, and may contribute to increased inbreeding. This trend may lead to long-term loss of genetic variability in the Polynesian lemon shark populations, even though natural philopatry in $N$. acutidens, which would have been a detrimental factor, seems to be low (Schultz et al. 2008).

Increasing residency was a general trend for the shark population. For all groups except Group B, which was composed of animals that disappeared, the linear regressions had positive slopes (Fig. 4), indicating an increase in shark abundance over time, and their site fidelity increased over the $44 \mathrm{mo}$, particularly for the 'resident' subgroups, C1 and C2 (Table 1). This means that, despite some sharks leaving and others arriving, the number of days with sharks present and the number of sharks at the site both increased. This trend is explained by the increased attraction of sharks by provisioning, suggesting that learning plays a strong role in optimising their food search (Guttridge et al. 2009). Our findings are consistent with similar situations where other elasmobranchs (rays) learned to associate specific locations with food rewards, with detrimental effects on their behaviour, and indirect effects on the surrounding marine ecosystems, leading to the concept of an 'ecological trap' (Corcoran 2006, Gaspar et al. 2008, Semeniuk \& Rothley 2008). In the case of lemon sharks, their increased site fidelity can have a negative effect on gene flow, as mentioned previously, and can also affect their role as top predators in the area, as shown for top terrestrial predators such as dragons Varanus komodoensis in the Komodo National Park, where provisioning was eventually banned (Walpole 2001).

Among the negative effects, we observed intraspecific interactions generated by the provision of a limited amount of food. Not all sharks present during a dive acquired food, and this resulted in exacerbated competition among the animals. This pattern can lead to increasing the number of intraspecific dominance actions and the aggression of sharks to acquire food (Ritter 2001), as shown for rays (Semeniuk \& Rothley 2008). Dominance is often driven by the size (length) of the sharks in social groups (Allee \& Dickinson 1954, Myrberg \& Gruber 1974). During several feeding sessions, the largest resident male, M04, appeared to be the most inquisitive, approaching the divers closer than any other individual did. Since males M07 and M18 were dominant in 2005, M04 definitely acquired increasing dominance behaviour with respect to other individuals, which turned into deliberate aggression towards other males when several of them were present. As was previously observed in 2005 for its 2 predecessors, from 2006 onwards M04 often arrived in the morning with fresh scars or notches that can be attributed to intraspecific fights (N. Buray pers. obs.). Aggression increased significantly when resident males came back to the feeding site after the mating period, probably in the context of a reorganisation of the hierarchy, as shown by serious wounds on males that were quite different in their severity and locations from those inflicted on females during mating (Fig. 5). In natural conditions, sicklefin lemon sharks cannot be considered a gregarious species (Stevens 1984), except during the mating period, and animals usually feed separately. Therefore, intraspecific aggression linked to the feeding process, even though natural among carnivorous animals, can be interpreted as deviant behaviour, exacerbated by human activity. Although managers may consider this process of increasing intraspecific aggression to be acceptable among sharks, it represents a real issue regarding the safety of divers for whom the risk of accidental bites has increased critically (Burgess 1998). Between 1979 and 2001, $47 \%$ of shark bites in French Polynesia were experienced in the context of shark-feeding activities (Maillaud \& Van Grevelynghe 2005). Although anecdotal, this was confirmed by a serious bite by shark 

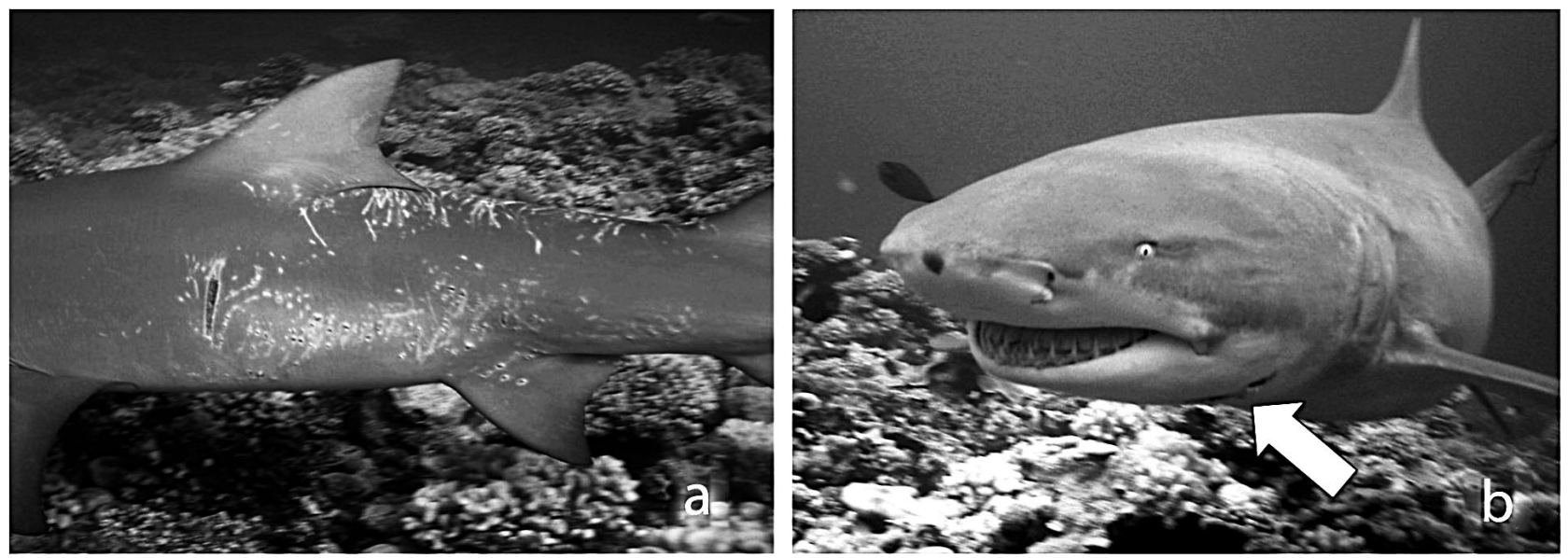

Fig. 5. Negaprion acutidens. (a) Mating scars (white lines and dots) in the middle and posterior part of the body of a female lemon shark, and (b) a bite wound located on the throat (arrow) of a male lemon shark, inflicted during intraspecific male-male fighting for dominance (photos by N. Buray)

M04 on the left hand, which was not holding any food, of the diver doing the feeding in January 2006 (N. Buray pers. obs.).

The results of this study indicate that in spite of the provisioning activity, several male and female sicklefin sharks seem to have left the study site while others came back to it for mating. This positive aspect from the perspective of maintaining gene flow between this shark population and adjacent ones is mitigated by the increasing pattern of residency for the overall population during the study. At present, the population seems to be a balanced mix of resident and non-resident individuals, which favours population mixing. However, if the resident sharks increase their numbers and their attachment to the feeding site, group living can generate costs for animals which are normally solitary foragers, such as injuries, predation, increased stress hormone levels and exposure to parasites due to increased transmission rates between individuals (Semeniuk \& Rothley 2008). If supplemental feeding can be perceived as an artificial support to sharks by providing easy-to-access resources (Milazzo et al. 2006, Laroche et al. 2007), and can allow increasing energy allocation to other fitness-related activities such as rest and reproduction (Orams 2002), long-term unnatural aggregation can also have long-term fitness consequences for the population. Because the studied population is small, daily aggregations at the same location could result in increased social interactions and increased mating between close relatives, reinforcing the risk of inbreeding. As lemon sharks are known for their polyandry (Feldheim et al. 2004), the potential negative effect on gene flow linked to the increasing residency pattern might be buffered by the multiple pater- nity process; this needs to be thoroughly monitored. This factor, added to the development of aggression and incremental risk of accidental bites to divers, should lead managers to seriously consider a revision of the regulations on shark-feeding in French Polynesia in order to reduce these risks. An annual cessation of the feeding activity for several months, preferably encompassing the mating period, is an obvious solution. Whereas our study allowed us to draw these preliminary conclusions, additional field investigations are required to better understand the long-term effects of provisioning on shark populations. Further work may also enable us to better understand the risks induced by feeding predators.

Acknowledgements. This study benefited from the financial support of the Direction à l'Environnement (DIREN) of French Polynesia and the scientific support of the Coordination Unit of the Coral Reef Initiatives for the Pacific (CRISP Programme), based in Noumea, New Caledonia. We thank the private diving company Top Dive in Moorea for logistic support, and R. Galzin, Centre de Recherche Insulaire et Observatoire de l'Environnement (CRIOBE), J. Werry (University of Griffith) and M. Francis (National Institute of Water and Atmospheric Research), for scientific support.

\section{LITERATURE CITED}

Allee WC, Dickinson JC (1954) Dominance and subordination in the smooth dogfish Mustelus canis (Mitchill). Physiol Zool 27:356-364

- Bansemer CB, Bennett MB (2008) Multi-year validation of photographic identification of grey nurse sharks, Carcharias taurus, and applications for non-invasive conservation research. Mar Freshw Res 59:322-331 
Bookbinder MP, Dinerstein E, Rijal A, Cauley H, Rajouria A (1998) Ecotourism's support of biodiversity conservation. Conserv Biol 12:1399-1404

Bres M (1993) The behaviour of sharks. Rev Fish Biol Fish 3:133-159

Brunnschweiler JM (2010) The Shark Reef Marine Reserve: a marine tourism project in Fiji involving local communities. J Sustain Tourism 18:29-42

Buray N, Mourier J, Planes S, Clua E (2009) Underwater photo-identification of sicklefin lemon sharks, Negaprion acutidens, at Moorea (French Polynesia). Cybium 33: 21-27

Burgess GH (1998) Diving with elasmobranchs: a call for restraint. IUCN Shark Specialist Group. Shark News 11: $1-4$

Chapman DD, Babcock EA, Gruber SH, Dibattista JD and others (2009) Long-term natal site-fidelity by immature lemon sharks (Negaprion brevirostris) at a subtropical island. Mol Ecol 18:3500-3507

Compagno LJV (1984) Sharks of the world. An annotated and illustrated catalogue of shark species known to date. Part 2. Carcharhiniformes. FAO Fisheries Synopsis 125, Vol 4, Part 2, FAO, Rome

Corcoran M (2006) The effects of supplemental feeding on the activity space and movement patterns of the southern stingray, Dasyatis americana, at Grand Cayman, Cayman Islands. MSc thesis, Nova Southeastern University, Fort Lauderdale, FL

DiBattista JD, Feldheim KA, Gruber SH, Hendry AP (2007) When bigger is not better: selection against large size, high condition and fast growth in juvenile lemon sharks. J Eur Soc Evol Biol 20:201-212

Dicken ML, Hosking SG (2009) Socio-economic aspects of the tiger shark diving industry within the Aliwal Shoal Marine Protected Area, South Africa. Afr J Mar Sci 31: $227-232$

Dobson J (2006) Sharks, wildlife tourism, and state regulation. Tourism Mar Environ 3:15-23

- Economakis AE, Lobel PS (1998) Aggregation behavior of the grey reef shark, Carcharhinus amblyrhynchos, at Johnston Atoll, Central Pacific Ocean. Environ Biol Fishes 51: 129-139

Feldheim KA, Gruber SH, Ashley MV (2002) Breeding biology of lemon sharks at a tropical nursery lagoon. Proc Biol Sci 269:1655-1662

Feldheim KA, Gruber SH, Ashley MV (2004) Reconstruction of parental microsatellite genotypes reveals female polyandry and philopatry in the lemon shark, Negaprion brevirostris. Evolution 58:2332-2342

Ferreira C, Ferreira T (1996) Observations on white sharks along the South African coast. In: Klimley AP, Ainley DG (eds) Great white sharks: the biology of Carcharodon carcharias. Academic Press, San Diego, CA, p 375-384

Garrod B, Wilson JC (2006) Nature on the edge? Marine ecotourism in peripheral coastal areas. J Ecotourism 12: 95-120

Gaspar C, Chateau O, Galzin R (2008) Feeding sites frequentation by the pink whipray Himantura fai in Moorea (French Polynesia) as determined by acoustic telemetry. Cybium 32:153-164

Gower JC (1966) Some distance properties of latent root and vector methods used in multivariate analysis. Biometrika 53:325-338

Gruber SH (1982) Role of the lemon shark, Negaprion brevirostris (Poey), as a predator in the tropical marine environment: a multidisciplinary study. Fla Sci 45:4-75
Guttridge TL, Myrberg AA, Porcher IF, Sims DW, Krause J (2009) The role of learning in shark behaviour. Fish Fish 10:450-469

Halpenny EA (2003) NGOs as conservation agents: achieving conservation through marine ecotourism. In: Garrod B, Wilson JC (eds) Marine ecotourism: issues and experience. Channel View Publications, Clevedon, p 107-121

Holm S (1979) A simple sequentially rejective multiple test procedure. Scand J Stat 6:65-70

ISAF (International Shark Attack Files) (2010) Species of sharks implicated in attacks on divers. Available at www. flmnh.ufl.edu/fish/sharks/scuba/Shark/Shark.htm

Johnson R, Kock A (2006) South Africa's white shark cagediving industry: Is there cause for concern? In: Nel DC, Peschak TP (eds) Finding a balance: white shark conservation and recreational safety in the inshore waters of Cape Town, South Africa. Proceedings of a Specialist Workshop, Capetown. WWF South Africa Report Series 2006/Marine/001, p 40-59

Klimley PA (1987) The determinants of sexual segregation in the scalloped hammerhead shark, Sphyrna lewini. Environ Biol Fishes 18:27-40

Laroche RK, Kock AA, Dill LM, Oosthuizen WH (2007) Effects of provisioning ecotourism activity on the behaviour of white sharks Carcharodon carcharias. Mar Ecol Prog Ser 338:199-209

Legendre P, Legendre L (1998) Numerical ecology, 2nd English edn. Elsevier Science BV, Amsterdam

> Maillaud C, Van Grevelynghe G (2005) Shark attacks and bites in French Polynesia. J Eur Urgences 18:37-41

Meyer CG, Dale JJ, Papastamatiou YP, Whitney NM, Holland KN (2009) Seasonal cycles and long-term trends in abundance and species composition of sharks associated with cage diving ecotourism activities in Hawaii. Environ Conserv 36:104-111

Milazzo M, Anastasi I, Willis TJ (2006) Recreational fish feeding affects coastal fish behavior and increases frequency of predation on damselfish Chromis chromis nests. Mar Ecol Prog Ser 310:165-172

> Morrissey JF, Gruber SH (1993) Habitat selection by juvenile lemon sharks, Negaprion brevirostris. Environ Biol Fishes 38:311-319

Mucientes GR, Queizoz N, Sousa LL, Tarroso P (2009) Sexual segregation of pelagic sharks and the potential threat from fisheries. Biol Lett 5:156-159

Myrberg AA, Gruber SH (1974) The behavior of the bonnethead shark, Sphyrna tiburo. Copeia 1974:358-373

Newsome D, Rodger K (2008) To feed or not to feed: a contentious issue in wildlife tourism. In: Lunney D, Munn A, Meikle W (eds) Too close for comfort: contentious issues in human-wildlife encounters. Royal Zoological Society of New South Wales, Mosman, p 255-270

> Orams MB (2002) Feeding wildlife as a tourism attraction, a review of issues and impacts. Tourism Manag 23:281-293

Raup DM, Crick RE (1979) Measurement of faunal similarity in paleontology. J Paleontol 53:1213-1227

Ritter EK (2001) Food-related dominance behaviour between two carcharhinid shark species, the caribbean reef shark, Carharhinus perezi, and the black tip shark, Carharhinus limbatus. Mar Fresh Behav Physiol 34:125-129

Schultz JK, Feldheim KA, Gruber SH, Ashley MV, McGovern TM, Bowen BW (2008) Global phylogeography and seascape genetics of the lemon sharks (genus Negaprion). Mol Ecol 17:5336-5348

> Semeniuk CAD, Rothley KD (2008) Costs of group-living for a normally solitary forager: effects of provisioning tourism 
on southern stingrays Dasyatis americana. Mar Ecol Prog Ser 357:271-282

Stevens JD (1984) Life-history and ecology of sharks at Aldabra Atoll, Indian Ocean. Proc R Soc Lond B Biol Sci 222:79-106

- Topelko KN, Dearden P (2005) The shark watching industry and its potential contribution to shark conservation. J Ecotourism 4:108-128

Editorial responsibility: Tim McClanahan, Mombasa, Kenya
Walpole MJ (2001) Feeding dragons in Komodo National Park: a tourism tool with conservation complications. Anim Conserv 4:67-73

White WT, Platell ME, Potter IC (2004) Comparisons between the diets of four abundant species of elasmobranchs in a subtropical embayment: implications for resource partitioning. Mar Biol 144:439-448

Submitted: March 11, 2010; Accepted: July 25, 2010

Proofs received from author(s): September 4, 2010 